\title{
Comparison of Obstetric Efficacy and Safety of the Kiwi OmniCup with Conventional Vacuum Extraction
}

\author{
Vergleich der geburtshilflichen Effektivität und Sicherheit des Kiwi OmniCup \\ mit der konventionellen Vakuumextraktion
}

Authors

Affiliations
W. Siggelkow ${ }^{1}$, N. Schwarz ${ }^{2}$, M. W. Beckmann², S. Kehl' ${ }^{2}$, F. Faschingbauer ${ }^{2}$, R. L. Schild ${ }^{3}$

1 Department of Gynaecology, Diakonische Dienste Hannover GmbH, Hannover

2 Erlangen University Hospital, Obstetrics and Gynaecology, Erlangen

${ }^{3}$ Department of Obstetrics and Perinatal Medicine, Diakonische Dienste Hannover GmbH, Hannover

\section{Key words \\ Q birth \\ - birth trauma \\ - delivery \\ Schlüsselwörter \\ - Geburt \\ - Geburtstrauma \\ - Geburtshilfe}

\section{received 16.4.2013 \\ revised 26.11.2013 \\ accepted 9.1.2014}

\section{Bibliography}

Dol http://dx.doi.org/

10.1055/s-0033-1360343

Published online 26.2.2014

Geburtsh Frauenheilk 2014; 74 :

146-151 @ Georg Thieme

Verlag KG Stuttgart · New York . ISSN 0016-5751

\section{Correspondence}

\section{Wulf Siggelkow MD}

Diakonische Dienste Hannover $\mathrm{GmbH}$

Diakoniekrankenhaus Henriettenstiftung

Schwemann-Straße 17

30559 Hannover

wulf.siggelkow@ddh-gruppe.de

\section{Abstract \\ V}

Purpose: The aim of the present study was to compare the safety and efficacy of the Kiwi OmniCup system with conventional vacuum delivery. Methods: A retrospective study of operative vaginal deliveries was done for 4682 births. The procedures included 217 operative vaginal deliveries (4.6\%), 79 of which were done using conventional vacuum extraction (37\%) and 138 using the Kiwi system (63\%).

Results: Use of the Kiwi system was associated with a significant reduction in episiotomies (61 vs. $76 \%$ in the control group; $\mathrm{p}<0.05$ ). The rates of successful completion of birth were comparable for the two systems (94\% with the Kiwi system and $99 \%$ with conventional vacuum delivery). Cup detachment occurred significantly more often in the Kiwi group $(p<0.005)$, requiring a change to a different method of birth significantly more often. It was necessary to change the procedure significantly more often from the mid-pelvis $(p<0.05)$. The incidence of maternal and foetal injuries was similar for the two systems.

Conclusions: With regard to obstetric efficacy and safety and foetal and maternal injuries, the Kiwi system is an acceptable alternative to the conventional vacuum cup. The advantages of the Kiwi system are its significantly lower episiotomy rate and its ease and rapidity of use.

\section{Zusammenfassung \\ $\nabla$}

Zielsetzung: In der vorliegenden Untersuchung werden die Sicherheit und Effektivität des KiwiOmniCup-Systems mit der konventionellen Vakuumentbindung verglichen.

Methodik: Es wurde eine retrospektive Untersuchung vaginal-operativer Entbindungen aus einer Gesamtzahl von 4682 Geburten vorgenommen. Von diesen Patientinnen hatten 217 eine vaginal-operative Entbindung (4,6\%), davon 79 mithilfe konventioneller Vakuumextraktion (37\%) und 138 mit dem Kiwi-System (63\%).

Ergebnisse: Der Einsatz des Kiwi-Systems ging mit einer signifikanten Reduktion der Episiotomien einher (61 vs. 76\% in der Kontrollgruppe, $\mathrm{p}<0,05)$. Der Anteil erfolgreich zu Ende gebrachter Entbindungen war vergleichbar für beide Systeme (94\% mit dem Kiwi-System und 99\% mit konventioneller Vakuumentbindung). Ein Abreißen der Glocke trat signifikant häufiger in der Kiwi-Gruppe auf $(p<0,005)$ und zog somit signifikant häufiger den Wechsel auf einen anderen Geburtsmodus nach sich. Eine solche Notwendigkeit zum Verfahrenswechsel trat signifikant häufiger von der Beckenmitte auf ( $p<0,05)$. Mütterliche wie kindliche Verletzungen traten in beiden Systemen mit gleicher Inzidenz auf.

Schlussfolgerungen: Das Kiwi-System stellt hinsichtlich der geburtshilflichen Effektivität wie auch der Sicherheit im Hinblick auf fetale und mütterliche Verletzungen eine adäquate Alternative zur konventionellen Vakuumglocke dar. Das Kiwi-System sticht im Vergleich durch seine signifikant geringere Episiotomierate und die einfache und zügige Handhabung hervor. 


\section{Introduction}

$\nabla$

Several procedures for operative vaginal delivery have been identified as major risk factors for foetal morbidity and mortality as well as early and late maternal morbidity including pelvic floor disease [1]. These procedures were used in 5-26\% of nulliparous deliveries [2]. Historically, the vacuum is considered the instrument of choice due to a posited reduction in maternal injuries, although long-term follow-up suggests no difference in pelvic floor function between women who have undergone vacuum delivery and those who have had forceps delivery $[3,4]$.

Clinical guidelines and protocols have been introduced in many labour ward settings to reduce complications and ensure optimum outcomes for both mothers and neonates $[5,6]$. Various modifications of vacuum extractor cups have been made since their first introduction by Malmström in the 1950s. Among the newer developments are the Bird cup for posterior position application, the soft cup and the most recent addition, the Kiwi OmniCup [3,7].

The basic premise of any vacuum device is that a suction cup, made of silastic or metal material, is connected, via tubing, to a vacuum source. Traction is then applied to the presenting part, the foetal vertex, to expedite delivery, either directly through the tubing or using a traction chain.

Determination of the flexion point is vital for successful vacuum extraction. In an average term infant, this point is located on the sagittal suture $3 \mathrm{~cm}$ anterior to the posterior fontanelle, and thus $6 \mathrm{~cm}$ posterior to the anterior fontanelle. However, not all vacuum cup designs allow easy positioning over the flexion point, especially when the foetal head adopts an occipito-posterior or lateral position.

Today, operative vaginal delivery using the vacuum cup is one of the most common instrument procedures used in obstetrics $[2,3$, 7,8 ]. Randomised studies and meta-analyses have shown that risks to mother and child are mainly associated with changes in obstetric instrumentation when vacuum extraction fails [9-12]. This study examined the safety and obstetrical efficacy of a single-use instrument, the Kiwi OmniCup, compared with conventional vacuum extraction in operative vaginal deliveries.

The Kiwi OmniCup is a single-use instrument with an integrated hand pump. The flexible suction and traction element is inserted centrally. When lateral traction is applied, the traction element slips into the groove designed for that purpose that runs from central to lateral in the flat outer part of the cup. The cup can be deployed in both anterior and posterior cephalic presentation. The system is designed to make rotation of the head easier compared with conventional vacuum suction cups [13]. The Kiwi system was approved worldwide following publication of the paper by Richard Hayman [3].

Even at the time when the traditional suction cup still in use today was being developed by Bird [14], eccentric positioning of the cup over what is known as the flexion point was described. This point has a more occipital position than the small fontanelle; it allows optimal flexion of the head in the direction of the traction exerted by the system. This makes it possible to correct mal-positioning of the head [15].

The aim of this study was to compare the efficacy of both instruments by assessing the respective numbers of completed births and the rates of drop-offs for both instruments. The number of multiple attempts due to detachment of the cup and the number of changes in obstetrical procedure are shown for both groups.

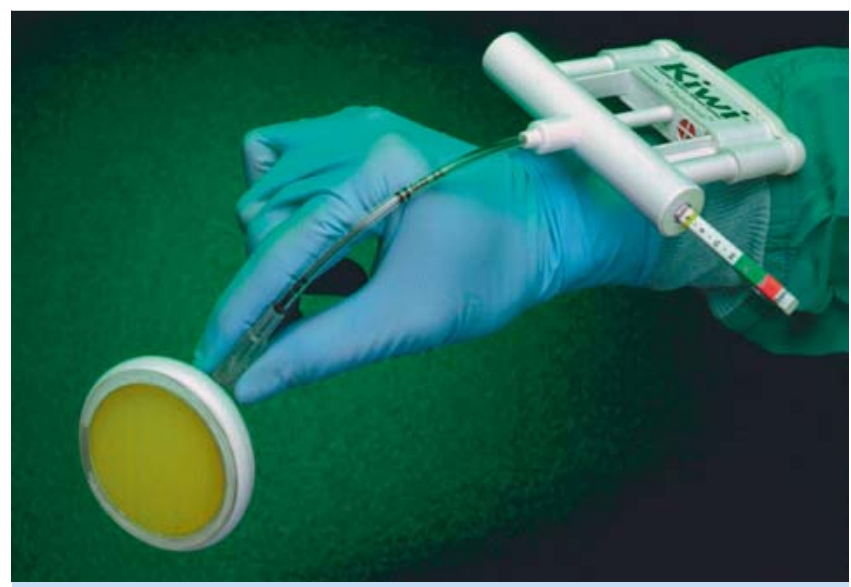

Fig. 1 Kiwi OmniCup, with the permission of Brenner Medical GmbH.

Secondary outcome measures were neonatal and maternal outcome in both groups who had undergone assisted vaginal delivery. The impact on neonatal safety was assessed by paediatricians following assisted vaginal delivery. Paediatric examinations focussed on intracranial and extracranial head injuries. Maternal safety was also assessed, and the occurrence of perineal tears or maternal injury in the birth canal was noted.

\section{Methods}

$\nabla$

Data were collected retrospectively using hospital records. Kiwi systems were provided by Brenner Medical GmbH ( Fig. 1) and conventional vacuum-systems by Medela GmbH. Deliveries were carried out using conventional vacuum extraction or Kiwi delivery alternately to obtain comparable numbers for both procedures for every obstetrician. All assisted vaginal deliveries in this study were performed by senior physicians. Only patients with foetuses with a gestational age $>34$ weeks were included in the study. All pregnancies were single pregnancies.

\section{Obstetrical data}

The mean period of gestation was 279.24 days (range 240-295 days). The mean period of gestation for the Kiwi OmniCup delivery group was 279.12 days (range 240-295 days). In the group who had conventional vacuum delivery, the mean period of gestation was 279.43 days (range 248-293 days). There were 162 nulliparous mothers in the study (75\%). Fifty-five women (25\%) were multiparas. In the Kiwi group, 104 women (75\%) were nulliparas; in the vacuum group, this figure was 58 (73\%).

\section{Indications for vaginal assisted delivery}

Obstetrical reasons for operative vaginal delivery consisted of protracted second stage of labour, with or without deflexion, or presentational anomalies.

Foetal indications such as pathological cardiotocography (CTG) findings, foetal hypoxaemia and foetal acidosis, and maternal indications such as exhaustion or a contraindication against bearing down (due to cardiopulmonary or cerebrovascular disease) were outcome variables in the comparison of the two instruments. Indications such as pathological cardiotocography (CTG) were defined according to the current guidelines of the German Society for Obstetrics and Gynaecology (DGGG). Foetal acidosis 


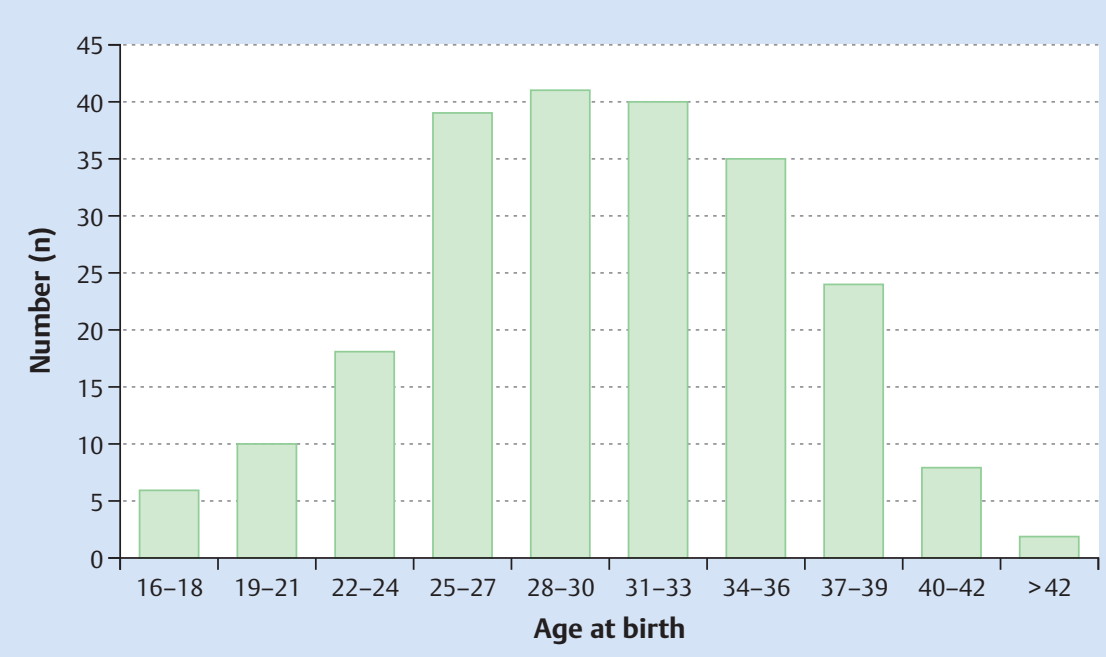

Fig. 2 Age at birth (all patients).

was confirmed with micro-blood analysis. Arrest of labour, protracted second stage of labour and maternal exhaustion were treated by augmentation of labour using oxytocin $[5,6]$.

\section{Delivery data collection}

Each birth was documented and subsequently evaluated using a standardised protocol for maternal demographic data which included the indication for vacuum extraction, course of birth, neonatal data, maternal and neonatal birth injuries, further paediatric therapy, and complications with the obstetrical instrument.

The length of the second stage of labour and foetal station and position at the time of instrumentation were determined using the birth records. Foetal position was classified as sinciput, occipito-anterior, occipito-posterior, or brow presentation. Foetal station was classified using the DeLee system parallel level system as mid-pelvis, pelvic floor, and pelvic outlet.

Creation of an episiotomy and the occurrence of perineal tears (first to fourth degree), as well as any maternal injuries in the birth canal, were documented.

The efficacy of the instruments was determined based on the rate of completed births for each instrument. The numbers of "dropoffs" - detachments of the respective system - and the need for subsequent instrumentation or secondary Caesarean section were determined using the birth records.

\section{Neonatal data collection}

The usual neonatal data were collected (Apgar score, pH, height, weight, head circumference). Neonatal birth injuries were assessed by a paediatrician. After operative vaginal delivery, all infants received a paediatric examination, which focussed on intracranial and extracranial head injuries during birth, and any transfers to the paediatric department were documented.

\section{Statistical analysis}

Data are presented as means, ranges and intervals. Pearson's correlation test was used to analyse correlations between the two groups. Nonparametric tests, Wilcoxon test (for paired samples), and Mann-Whitney U test (for unpaired samples) were used for statistical analysis. Significance levels of $p<0.05$ were set for all statistical analyses. Statistical and graphical processing of the data was carried out using SPSS, version 13.0 (IBM SPSS, Armonk, New York, USA).

\section{Results}

$\nabla$

Study population and indication

for obstetrical procedures

A retrospective study of operative vaginal deliveries in the period from 2003 to 2005 was carried out. The total number of births in the Department of Gynaecology at the University of ErlangenNuremberg in this period was 4682.217 of these births were operative vaginal deliveries (4.6\%), of which 79 were done with conventional vacuum extraction (37\%) and 138 with the Kiwi system (63\%). There was no difference in patient age between both groups. Age distribution at birth is given in $\bullet$ Fig. 2 .

Gestational age at birth was comparable between both groups. A total of 138 women (64\%) received oxytocin intrapartum for augmentation of labour. Induction of labour was similarly distributed between the two groups. This applies in particular to peridural catheter placement intrapartum (69\% of all patients) and opiate administration (32\%).

There were no differences in the distribution of individual indications between groups. Fifty-four (25\%) of the operative vaginal deliveries were carried out from the mid-pelvis, 134 (63\%) from the floor of the pelvis, and 29 (13\%) from the pelvic outlet. The two methods of operative vaginal delivery were comparable with regard to the indications relative to the station of the foetal head at instrumentation. These data including foetal position at the time of instrumentation are summarised in 0 Table 1.

Duration of the second stage of labour was $2.56 \mathrm{~h}$ (range $0.3-$ $3.6 \mathrm{~h}$ ), with no relevant differences between the two groups.

\section{Maternal outcome postpartum}

A mediolateral episiotomy was made in a total of 144 women (66\%). Episiotomies were done in 84 women (61\%) in the Kiwi group and 60 (76\%) in the vacuum group. The higher number of episiotomies in the conventional vacuum group was statistically significant $(\mathrm{p}<0.05)$. Extension to a third-degree perineal tear with the episiotomy occurred in 22 cases (15\%) of the overall population. When no episiotomy was done, there were seven third-degree perineal tears (9\%) in the whole population. There were no significant differences between study groups.

Overall, 33 patients (15\%) suffered a second-degree perineal tear and 29 patients $(13.5 \%)$ had third-degree perineal tears. Fourthdegree perineal tears occurred in two cases (1\%). Twenty-six pa- 
Table 1 Indications for operative vaginal delivery for both instruments, including foetal station and presentation.

\begin{tabular}{|c|c|c|c|c|}
\hline \multirow[t]{2}{*}{ Indication } & \multicolumn{2}{|c|}{ Kiwi OmniCup } & \multicolumn{2}{|c|}{ Vacuum } \\
\hline & $\mathbf{n}$ & $\%$ & $\mathbf{n}$ & $\%$ \\
\hline Micro-blood analysis & 0 & 0 & 1 & 1 \\
\hline Cardiotocography anomaly & 82 & 59 & 37 & 47 \\
\hline Maternal exhaustion & 5 & 4 & 4 & 5 \\
\hline Arrest of labour & 34 & 24 & 18 & 23 \\
\hline Protracted second stage & 16 & 12 & 16 & 20 \\
\hline Other & 1 & 1 & 2 & 2.5 \\
\hline \multicolumn{5}{|l|}{ Foetal station at indication } \\
\hline Mid-pelvis & 35 & 25 & 19 & 24 \\
\hline Pelvic floor & 88 & 64 & 46 & 58 \\
\hline Pelvic outlet & 15 & 11 & 14 & 18 \\
\hline \multicolumn{5}{|c|}{ Foetal presentation at indication } \\
\hline Sinciput & 10 & 7.5 & 8 & 10 \\
\hline Occipito-anterior & 122 & 88 & 68 & 86 \\
\hline Occipito-posterior & 4 & 3 & 3 & 4 \\
\hline Brow & 2 & 1.5 & 0 & 0 \\
\hline
\end{tabular}

tients (19\%) in the Kiwi group had a second-degree perineal tear, and $22(16 \%)$ had a third-degree perineal tear. No fourth-degree perineal tears occurred in the Kiwi group. In the vacuum group, second-degree and third-degree perineal tears occurred in seven cases each $(8 \%)$. Two women (2\%) had a fourth-degree perineal tear. This difference was not significant at the defined level of significance.

\section{Neonatal outcome postpartum}

Neonatal data are shown in 0 Table 2 . There were no significant differences with regard to height or weight, or Apgar and $\mathrm{pH}$ values. Cephal haematomas occurred in 14 neonates (6\%) and caput succedaneum in 13 cases (6\%), with no significant differences between groups.

The number of cases of intracranial bleeding was $11(5 \%)$, with a slight trend towards a higher incidence in the group with conventional vacuum extraction (four versus seven). However, this trend was also not significant.

There were also no differences between the two groups with regard to the numbers of difficult shoulder descents/shoulder dystocias and the number of transfers of infants to the paediatric department.

\section{Reliability of the two operative vaginal systems}

Analysis of all the operative vaginal births in this study showed that births were successfully completed using instruments in 208 cases (96\%). Successful completion was achieved with conventional vacuum extraction in 78 cases (99\%) and using the Kiwi system in 130 cases (94\%). The failure rates were 6\% in the Kiwi group and $1 \%$ in the conventional vacuum group.

Multiple attempts due to detachment of the cup were necessary in 17 cases (8\%) in the overall group, with 15 cases (11\%) occurring in the Kiwi group and two (3\%) in the group delivered using conventional vacuum extraction. Detachment of the operative vaginal instrument requiring a change in birth method occurred significantly more often in the Kiwi group $(p<0.05)$. Overall, the procedure had to be changed in nine cases ( $4 \%$ ). 0 Table 4 gives a summary of intrapartum changes of obstetrical procedure. The need to change procedure occurred significantly more often from the mid-pelvis $(\mathrm{p}<0.05)$.
Table 2 Neonatal data postpartum for all neonates and both procedures.

\begin{tabular}{|l|ccr|}
\hline & All births & Kiwi & \multicolumn{1}{l}{ Vacuum } \\
\hline Birth weight $(\mathrm{g})$ & $3384 \pm 470$ & $3369 \pm 457$ & $3410 \pm 493$ \\
\hline Height $(\mathrm{cm})$ & $51.09 \pm 2.63$ & $50.89 \pm 2.56$ & $51.44 \pm 2.74$ \\
\hline $\begin{array}{l}\text { Head circumference } \\
(\mathrm{cm})\end{array}$ & $34.77 \pm 1.51$ & $34.73 \pm 1.51$ & $34.84 \pm 1.52$ \\
\hline Apgar score & & & \\
\hline$>1$ min & $7.98 \pm 1.57$ & $7.99 \pm 1.53$ & $7.95 \pm 1.64$ \\
\hline$>5$ min & $9.25 \pm 1.13$ & $9.21 \pm 1.25$ & $9.32 \pm 0.88$ \\
\hline 10 min & $9.65 \pm 0.92$ & $9.64 \pm 1.04$ & $9.67 \pm 0.67$ \\
\hline pH & $7.24 \pm 0.07$ & $7.24 \pm 0.07$ & $7.26 \pm 0.07$ \\
\hline Base excess & $-5.34 \pm 3.04$ & $-5.64 \pm 3.16$ & $-4.82 \pm 2.78$ \\
\hline
\end{tabular}

When a change in operative birth method was necessary, the number of more extensive perineal tears increased, irrespective of the group. An increase in severe paediatric injuries such as cephal haematoma or intracranial bleeding after multiple attempts with a switch to an alternative method of operative delivery also occurred independently of the procedure used. The increase in the incidence of maternal and neonatal injuries did not reach significance.

The station of the foetal head (mid-pelvis or pelvic floor) at the time of changing the procedure and mal-positioning (e.g., posterior vertex presentation) had no influence on the incidence of neonatal or maternal injuries in either group ( 0 Tables 3 and $\mathbf{4}$ ).

\section{Discussion}

The primary aim of this retrospective study was to compare the obstetrical efficacy of the Kiwi OmniCup with conventional vacuum delivery. Secondary outcome measures were a comparison of the safety data of the two systems, analysing the incidence of episiotomies and maternal and foetal injuries. Both Kiwi and conventional vacuum delivery were found to be highly effective, at 94 and 99\%, respectively. Prospective randomised studies done shortly after the introduction of the Kiwi OmniCup reported much poorer results for the Kiwi system, with failure rates of up to $28 \%$ [16] and $25.2 \%$ [13]. More recent studies have reported results more comparable to those found in the present study, with a

Table 3 Intrapartum changes in obstetrical procedure for both groups.

\begin{tabular}{|llll|}
\hline Procedure change & Forceps & Caesarean & Kiwi/vacuum \\
Overall & $7(3 \%)$ & $1(1 \%)$ & $1(1 \%)$ \\
\hline Kiwi & $6(4 \%)$ & $1(1 \%)$ & $1(1 \%)$ \\
\hline Vacuum & $1(1 \%)$ & 0 & 0 \\
\hline
\end{tabular}

Table 4 Severe neonatal injuries (cephal haematoma and intracranial haemorrhage) relative to foetal station.

\begin{tabular}{|c|c|c|}
\hline & $\begin{array}{l}\text { Cephal haematoma/ICH } \\
\text { Mid-pelvis }\end{array}$ & $\begin{array}{l}\text { Cephal haematoma/ICH } \\
\text { Pelvic floor }\end{array}$ \\
\hline Overall & $11(13 \%)$ & $13(10 \%)$ \\
\hline Kiwi & $6(12 \%)$ & $6(7 \%)$ \\
\hline Vacuum & $5(15 \%)$ & $7(15 \%)$ \\
\hline
\end{tabular}

$\mathrm{ICH}$ : intracranial haemorrhage 
success rate of $87 \%$ for Kiwi delivery and $91 \%$ for conventional vacuum delivery [3]. The obstetrician's experience with the system and the level of professional expertise plays a relevant role in the analysis of data in prospective randomised studies [17]. The slightly longer and more flexible traction mechanism in the Kiwi system can make it more difficult to apply the traction force precisely and steadily and to maintain an optimal direction of traction [13]. The station of the foetal head when the instrument is applied has been reported to have an important influence, corresponding to the present results. The success rates with both systems increase from a station of $\geq+2$ onward [18].

In the present study, detachment of the cup occurred in $8 \%$ of cases in the overall group. It occurred significantly more frequently in the Kiwi group, but no increase in the rate of neonatal injuries was observed.

The clear differences in success rates with the Kiwi system between the above reports and the present study may be due to the fact that the system was much more widely established at the time of the present analysis $[13,16]$. However, the evaluation of obstetrical data obtained mainly from experienced obstetricians in the present study may have resulted in bias. Essential operator-dependent prerequisites for obstetrical success include precise assessment of the station of the foetal head, optimal placement of the suction cup, and steady application of traction in the optimal direction [19].

Differences in the incidence of head injuries have been linked to the type of material used for the cup. Suction cup materials such as metal or hard plastic are associated with a greater risk of injury than "soft cups" [3]. As the present data also confirm, comparison of the Kiwi system with conventional vacuum delivery showed that there was no increase in the risk of intrapartum injuries to the foetal head $[16,19]$.

Intracranial injuries such as intracranial haematomas occur in five to six of every 10000 deliveries. Significant differences in the range of causes are seen with forceps delivery. According to a study by Jhawar et al. [20], forceps delivery increases the risk of intracranial injury five- to sixfold. The sequential use of forceps after a previous attempt at vacuum delivery also increases the risk of intracranial haemorrhage [21]. At present, there is no evidence that these figures can be influenced by different suction cup techniques.

Both in spontaneous births and operative vaginal deliveries, episiotomy reduced the incidence of severe maternal perineal injuries $[22,23]$. In our study, the indication for episiotomy depended on perineal tension. Perineal tension and the decision for episiotomy was assessed by the obstetrician. Youssef et al. [23] found nulliparity, infant birth weight and spinal anaesthesia to be associated with a greater use of episiotomy during assisted vaginal delivery. In this study, vacuum delivery was associated with a lower use of episiotomy compared to forceps delivery. Operator experience had an impact on episiotomy rates, with lower rates reported for the most experienced obstetricians. Attilakos et al. [16] and Vacca [24,25] analysed mediolateral episiotomies in Kiwi deliveries compared to conventional vacuum delivery. No influence on the number of higher-degree perineal injuries was noted. In contrast to the findings of the present study, these reports and the results published by Groom et al. [13] and Attilakos et al. [16] showed no differences in the incidence of episiotomy. The association between episiotomies and higher-degree perineal injury was examined by Youseff et al. [23]. Both during vacuum extraction and during forceps deliveries, episiotomy led to an increase in third-degree and fourth-degree perineal tears.
The significantly lower number of episiotomies in the Kiwi group in the present study was not associated with a reduction in more extensive perineal tears compared with the control group. This can be explained by the small number of third degree ruptures and a small study group.

There was a trend to higher numbers of third or fourth-degree tears with episiotomy (15\%) compared with $9 \%$ without episiotomy in the overall group, without the trend achieving significance. The preventative effect of avoiding episiotomy on the development of third and fourth-degree tears was confirmed in a study by Baskett et al. [4]. Episiotomies were carried out in 396 nulliparous patients who had Kiwi deliveries. Extension of the episiotomy to a third or fourth-degree perineal tear occurred in $17.2 \%$ of these patients compared with a rate of perineal tears of only $9.5 \%$ in the control group without episiotomy. Abstaining from episiotomy in multiparous patients in the study led to third-degree or fourth-degree perineal tears in only $2.8 \%$ of cases.

There is currently still insufficient valid data to resolve the debate conclusively on the protective effect of abstaining from episiotomy during vacuum deliveries $[4,26]$.

In contrast to other studies, the safety profile of the Kiwi system in the present study was also investigated in relation to maternal birth injuries such as labial, vaginal and cervical tears. No significant differences were found between the two groups.

Given the fact that financial resources are restricted, the price of the Kiwi single-use instrument must also be considered. The current purchase price for one Kiwi is $52.70 €$, which is similar to the cost of reprocessing a conventional vacuum.

\section{Conclusion \\ $\nabla$}

In summary, the Kiwi system represents an acceptable alternative to the conventional vacuum cup, in terms of obstetrical efficacy and safety with regard to foetal and maternal injury. The advantages of the Kiwi system are its significantly lower episiotomy rate and the ease and rapidity of use. As with all obstetrical instruments, however, the device must be used appropriately and correctly with strict adherence to the recommended safeguards for vacuum-assisted delivery.

\section{Conflict of Interest}

$\nabla$

None.

\section{References}

1 Franz HBG, Erxleben C, Franz A et al. Prevention of labour-associated pelvic floor injuries - what is known for sure. Geburtsh Frauenheilk 2012; 72: 804-808

2 Drife JO. Choice and instrumental delivery. Br J Obstet Gynaecol 1996; 103: 608-611

3 Hayman R, Gilby J, Arulkumaran S. Clinical evaluation of a 'hand pump' vacuum delivery device. Obstet Gynecol 2002; 100: 1190-1195

4 Baskett TF, Fanning CA, Young DC. A prospective observational study of 1000 vacuum assisted deliveries with the OmniCup device. J Obstet Gynaecol Can 2008; 30: 573-580

5 Berg D, Geiger W, Hickl EJ et al. Empfehlungen zur Dokumentation der Geburt - Das Partogramm; AWMF 015/017. Online: www.awmfonline.de

6 Dudenhausen J, Hopp H, Schneider KTM et al. Vaginal-operative Entbindungen; AWMF 015/023. Online: www.awmf-online.de

7 Ismail NA, Saharan WS, Zaleha MA et al. Kiwi Omnicup versus Malmstrom metal cup in vacuum assisted delivery: a randomized comparative trial. J Obstet Gynaecol Res 2008; 34: 350-353 
8 Chalmers JA, Chalmers I. The obstetric vacuum extractor is the instrument of first choice for operative vaginal delivery. Br J Obstet Gynaecol 1989; 96: 505-506

9 Johanson RB, Rice C, Doyle $M$ et al. A randomised prospective study comparing the new vacuum extractor policy with forceps delivery. $\mathrm{Br}$ J Obstet Gynaecol 1993; 100: 524-530

10 Johanson RB, Menon BK. Vacuum extraction versus forceps for assisted vaginal delivery. Cochrane Database Syst Rev 2000; 2: CD000224

11 Towner D, Castro MA, Eby-Wilkens E et al. Effect of mode of delivery in nulliparous women on neonatal intracranial injury. N Engl J Med 1999; 341: $1709-1714$

12 Murphy DJ, Liebling RE, Patel R et al. Cohort study of operative delivery in the second stage of labour and standard of obstetric care. BJOG 2003; 110: 610-615

13 Groom KM, Jones BA, Miller $N$ et al. A prospective randomised controlled trial of the Kiwi Omnicup versus conventional ventouse cups for vacuum-assisted vaginal delivery. BJOG 2006; 113: 183-189

14 Bird GC. The importance of flexion in vacuum extractor delivery. $\mathrm{Br}$ J Obstet Gynaecol 1976; 83: 194-200

15 Bird GC. The use of the Malmström vacuum extractor in operative obstetrics. Aust N Z J Obstet Gynaecol 1966; 6: 242-247

16 Attilakos G, Sibanda T, Winter C et al. A randomised controlled trial of a new handheld vacuum extraction device. BJOG 2005; 112: 1510-1515

17 Murphy DJ, Liebling RE, Verity L et al. Early maternal and neonatal morbidity associated with operative delivery in second stage of labour: a cohort study. Lancet 2001; 358: 1203-1207
18 Bofill JA, Rust OA, Schorr SJ et al. A randomized prospective trial of the obstetric forceps versus the M-cup vacuum extractor. Am J Obstet Gynecol 1996; 175: 1325-1330

19 McQuivey RW. Vacuum-assisted delivery: a review. J Mater Fetal Neonatal Med 2004; 16: 171-179

20 Jhawar BS, Ranger A, Steven D et al. Risk factors for intracranial hemorrhage among full-term infants: a case-control study. Neurosurgery 2003; 52: 581-590

21 Gardella C, Taylor M, Benedetti $T$ et al. The effect of sequential use of vacuum and forceps for assisted vaginal delivery on neonatal and maternal outcomes. Am J Obstet Gynecol 2001; 185: 896-902

22 de Leeuw JW, Struijk PC, Vierhout ME et al. Risk factors for third degree perineal ruptures during delivery. BJOG 2001; 108: 383-387

23 Youssef $R$, Ramalingam $U$, Macleod $M$ et al. Cohort study of maternal and neonatal morbidity in relation to use of episiotomy at instrumental vaginal delivery. BJOG 2005; 112: 941-945

24 Vacca A. Vacuum-assisted delivery. Best Pract Res Clin Obstet Gynaecol 2002; 16: $17-30$

25 Vacca A. Handbook of Vacuum Delivery in obstetric Practice. 2nd ed. Brisbane: Vacca Research; 2003: 35-67

26 Friedman EA, Sachtleben-Murray MR, Dahrouge D et al. Long-term effects of labor and delivery on offspring: a matched-pair analysis. Am J Obstet Gynecol 1984; 150: 941-945 